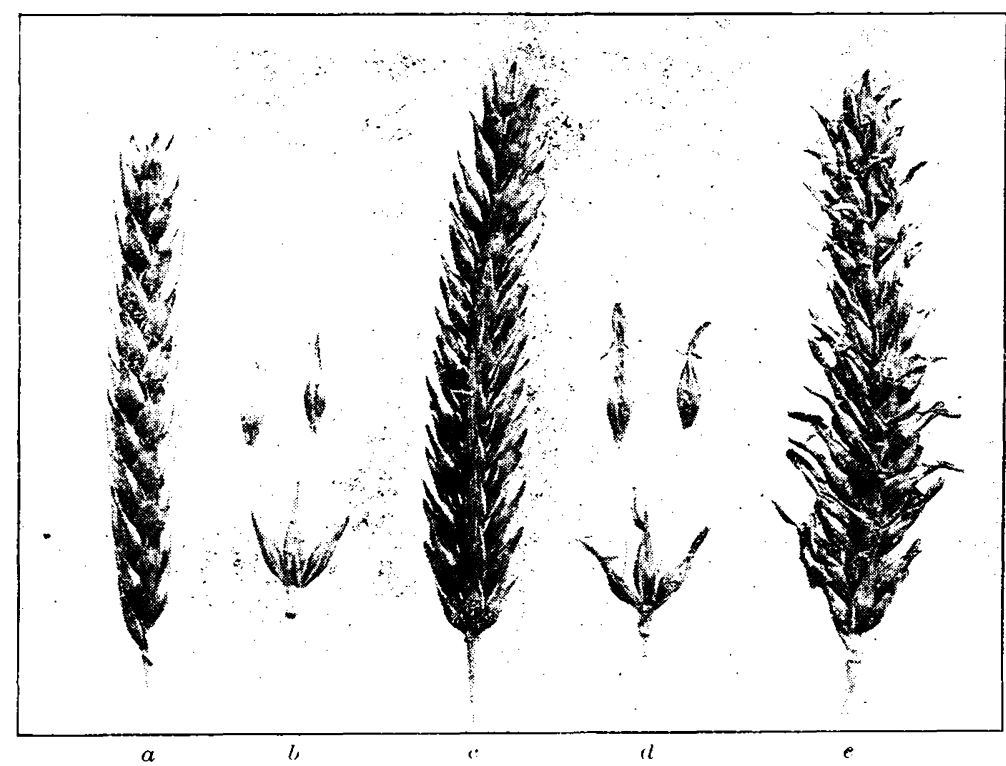

$a$, side view of head of new awnless barley; $b$, separate grains and spikelet; $c$, front view of the head; $d$, separate grains and spikelet of hooded barley; $e$, head of hooded barley.

the fall of 1907 and in 1908 produced heads similar to those in 1907 with the exception that on one plant were heads on which the greater portion of the lateral spikelets contained perfect kernels with short awns. The short-awned kernels from each head were planted in separate rows in the fall of 1908, and the plants produced from one of them in the summer of 1909 contained heads upon which all of the spikelets were fertile, the heads being six-rowed, with large plump grains without awns. The entire progeny was planted separately in the fall of 1909 in a head-to-row test, and of the several hundred heads produced in 191099 per cent. were of the awnless type. As this reduction of the awns was progressive and the heads have been awnless for two seasons, it is believed that the type is fixed. The variety has been named "Arlington." The fact that there is already a so-called type of beardless barley in existence will cause some confusion. It is proposed, therefore, that the name "hooded barley" be used for the old type, and this name will hereafter be used by the Office of Grain Investigations. The name beardless will only apply to the new hybrid.
The photograph illustrates both types.

H. B. DeRR

\section{THE AMERICAN CHEMICAL SOCIETY SAN FRANCISCO MEETING}

A GENERAL description of the meeting has already appeared in ScIEnce. The usual abstracts of papers have been delayed in publication, owing to the loss of a trunk in transit which contained many of them and has but recently been found.

The general session of the society was held at the St. Francis Hotel on Wednesday morning, July 13, at which the following papers were presented. An abstract of the last paper is the only one received.

Positive Photography: W. D. Bancroft.

(Il-

lustrated with lantern slides.)

Liquid Ammonia as a Solvent and the Ammonia System of Acids, Bases and Salts: E. C. FranKLIN.

Chemistry in the Bureau of Standards: W. F. HILLEBRAND.

The Use of Sodium Benzoate as a Preservative of Food: H. E. BABNARD.

To warrant its use in foodstuffs a preservative must possess certain characteristics. It must not injure the health of the consumer; it must not facilitate careless methods of manufacture; it 
must not allow the use of unfit raw material; it must be non-irritant; it must not retard the action of the digestive ferments; it must be an efficient preservative; it must not decompose into more active substances than itself. Sodium benzoate does not meet these requirements and its use is attended with so many disadvantages that it should not be allowed in foodstuffs.

Following the general session the society met as usual by divisions. The Division of Fertilizer Chemistry and the Sections of Biological Chemistry, Chemical Education and Chemistry of India Rubber held no meetings. Biological papers were therefore presented before the Division of Agricultural and Food Chemistry. Divisional meetings were held on July 14,15 and 16 with programs as follows:

DIVISION OF AGRICULTURAL AND FOOD CHEMISTRY

The Saccharimeter Scale and the Means of its

Verification: C. A. BRowne.

The various standards for the saccharimeter scale are described; methods of verifying scale divisions of a saccharimeter by means of quartz plates, the control tube and c. p. sucrose are given. The author has recalculated the sucrose values of the saccharimeter scale, using Landolt's formula and shows that the maximum error due to change of concentration is only $0.01^{\circ} \mathrm{V}$. The table of Schmitz which shows a maximum error of $0.08^{\circ} \mathrm{V}$. is erroneous. The statements of manufacturers that the wedge surfaces of saccharimeters are plane and the scale divisions equidistant are verified by practical tests upon modern instruments. The maximum error of graduation due to imperfections of quartz were not found to exceed $0.05^{\circ} \mathrm{V}$. upon two saccharimeters and were usually considerably within this limit. The relation between the French and German normal weights for sucrose according to measurements made upon a Laurent "plaque type" was 26 gms. to 16.29 gms., which agrees with the weights officially prescribed in Germany and France.

The Normal Weight of Dextrose: C. A. Browne.

The normal weight of dextrose for a saccharimeter, using the Ventzke scale, is given by different authorities as between 32.5 and 33 gms., according to the concentration of dextrose in solution taken as a basis of calculation. The author believes that the weight of pure dextrose, which, dissolved to 100 true c.c., will polarize exactly 100 at $20^{\circ} \mathrm{C}$., should be taken as the normal weight. The value thus calculated, using Tol- len's formula, is 32.25 gms. The actual dextrose value of the scale divisions of the saccharimeter, using this normal weight, is found by means of a table or a formula, which is correct for variations in specific rotation due to concentration. The advantage of using this method is that the per cent. of dextrose is found at one operation without the necessity of making a preliminary assay of material to determine the exact quantity necessary to be weighed out.

On the Oxidation of Pyrogallol by Hydrogen Peroxide in the Presence of Plant Extracts: $\mathrm{H}$. $\mathrm{H}$. BuNZEL.

Evidence is given that the oxidation of pyrogallol to purpurogallin by hydrogen peroxide in the presence of plant extracts takes place in two stages. The first is carried on by the hydrogen peroxide, the second by the oxidizing enzyme in the plant extract.

Detection of Lemon Oil in Orange Oil: E. M. Chace and A. R. Arbright.

The method employed depends upon the difference in the refractive indices of the aldehydes contained in lemon oil and in orange oil. The aldehydes are separated by formation of double sulphite compounds, which are decomposed by means of sodium carbonate and caustic soda under ether. The ether is evaporated and the refractive index of the remaining oil taken after drying and thorough purification. It is found that the refractive index of the aldehydes from lemon oil are almost identical with citral, while the aldehydes from both sweet and bitter orange oil are very much lower. The method is only very roughly quantitative.

The Influence of the Ingestion of Spices upon the Excretion of Hippuric Acid: H. E. BARNARD.

It has long been known that hippuric acid formerly found in the urine of man and in larger quantities in the urine of the herbivorous animals is produced by pairing of glycocol with benzoic acid. The origin of the benzoic acid eliminated as hippuric acid has usually been attributed to the ingestion of plant foods, fruits, etc., in which benzoic acid sometimes occurs naturally.

It has also been stated that the ingestion of spices containing essential oils of the aromatic series induces the increased excretion of hippuric acid, and to determine this point the hippuric acid was determined in the urine of seven subjects for four days, during which time the subjects ate normal food, and later for seven days when each subject was takino a bottle of 
catsup per day. The results showed no increase in hippuric acid excretion during the period when the tomato catsup was taken. The theory that the essential oils of spices are oxidized to benzoic acid is not sustained.

A careful study of the Bunge-Schmiedeberg method of determining hippuric acid showed the method as modified by Dakin to give accurate results.

The Reactions of Lime and Gypsum on some Oregon Soils: C. E. BRADLEY.

The soils of western Oregon respond very readily to applications of gypsum. Tests on a number of these soils with lime and gypsum under different conditions indicate that gypsum here acts as an indirect potash fertilizer, while lime does not.

\section{Environmental Studies on Wheat: H. W. WILEY} and J. A. LECrerc.

This paper contained a review of past work carried on in the bureau of chemistry on the influence of environment on the composition of wheat. The results showed that there was a larger difference in per cent. protein and weight per thousand grains between the same variety of wheat grown in different localities than between different varieties grown in the same locality. The average difference in nitrogen content between different varieties grown in the same locality is 0.69 per cent, the variation being from .11 to 1.25 per cent. This is based on 514 samples. The average difference in nitrogen content in the same variety grown in different localities is 1.23 per cent., the variation being .47 to 2.17 per cent. This is based on 449 samples representing forty varieties. There is no marked difference in ash, fat, fiber, pentosans or sugar between high and low nitrogen wheats. The length of the whole growing period influenced the nitrogen content, a long period of growth producing low nitrogen wheat, and vice versa.

The Translocation of Plant Food and Elaboration of Plant Material during Germination of Wheat: J. A. LeClerc and J. F. Breazeale.

At two days old when the germ of 100 seeds weighed about .2 grams, $i$. e., about 6 per cent. of the weight of the seed, the plantlet contained 42 per cent. of the total potash, 23 per cent. of the nitrogen, and 17 per cent. of the phosphoric acid. The formation of fat, fiber, sugars and pentosans was studied throughout the growing period. The fat in the seed decreased 30 per cent. in four days, after which there was no further decrease, thus showing that there had been no absorption of non-embryo fat of the seed into the plant. A small amount of fat was elaborated by the plant.

After fifteen days the residual seed contained about the same quantity of fiber as was originally present in the seed. The plantlet, however, formed six to seven times as much fiber as was present in the seed.

The residual seed gradually loses pentosans until less than half the original amount is present at the end of fifteen days. In the plant the amount of pentosans increased up to the tenth day, then decreased slightly. Cane sugar gradually decreased in the residual part of the seed until none was present at the end of the fifteenth day. In the plantlet, invert sugar increased up to the ninth day, when it contained three times more than the amount of total sugar of the original seed, and then decreased to the fifteenth day. The cane sugar of the plant increased to the twelfth day and then decreased. The decrease of sugars is probably due to their conversion into pentosans, part of which are later converted into tiber.

Time Factors in the Determination of Nitrogen and other Observations on the K Keldahl Method: P. L. HibBard.

Organic substances such as blood or bone have their nitrogen completely converted into ammonia by boiling three hours with 25 c.c. of sulphuric acid, 10 grams potassium sulphate and $\frac{1}{2}$ gram copper sulphate; in most cases.

In distillation of this digestion practically all the ammonia is obtained in less than fifteen minutes.

Bumping of the digestion is prevented by addition of one to two grams ferrous sulphate.

Using the Ulsch-Street method, only a few minutes are required to change the nitrogen of nitrates to ammonia.

During the acid digestion loss of ammonia occurs when a large portion of the acid has been driven out by too much or too long-continued heat, but not because the flask is heated by the bare flame above the level of the acid.

Composition and Digestibility of the Fat of Cowpea Hay: G. S. FraPs and J. B. RATHer.

The ether extract of cowpea hay has a digestibility with sheep of approximately 30 per cent. It contains over 50 per cent. unsaponifiable matter. The fatty acids have a digestibility of approximately 90 per cent. The unsaponifiable part 
of cowpea hay is only slightly soluble in water, but approximately 40 per cent. of the ether extract of the excrement is easily soluble in water. Full details and conclusions will be published elsewhere.

Determination of Ammonia Nitrogen in Water in the Presence of Hydrogen Sulphide: E. BARTow and B. H. HARRISON.

To the water containing hydrogen sulphide 50 c.c. of normal sulphuric acid was added and 100 c.c. of water distilled over. 50 c.c. of normal sodium hydroxide was then added snd ammonia determined by distillation and nesslerization. The hydrogen sulphide did not interfere with the ammonia determination and the addition of sulphuric acid was shown to have no appreciable effect on the regular determination of free and albuminoid ammonia.

Extent and Composition of the Incrustation on Filter Sands: E. BARTow and C. E. MILLAR.

Examinations were made of sand from five water purification plants in Illinois which use lime and sulphate of iron as a coagulent. By means of acid from 13 to 84 per cent. of incrustation was dissolved. This is equivalent to an increase of from 16 to 650 per cent. in the weight of the original sand. As the amount of sand in the beds was not increased, an amount of sand equal to the soluble matter has passed into the sewer. The soluble matter consisted of from 86 to 96.5 per cent. $\mathrm{CaCo}_{3}$.

High Protein Bread: J. A. LeClenc and B. R. JACOBS.

The results of baking tests show that a wellpiled loaf, of fair size, attractive in appearance, and palatable, can be made out of 25 per cent. cotton-seed flour and 75 per cent. ordinary flour. The protein content of such cotton-seed bread is over 14 per cent., while of bread made from ordinary flour it is under 9 per cent.

A Note on the Hypoxanthine of Meat: C. B. BennetT.

When fresh rabbit meat, or meat coagulated by heating to $75^{\circ} \mathrm{C}$., is extracted with water and the filtrate treated with barium hydroxide and basic lead acetate, almost no hypoxanthine is obtained in the final filtrate. Meat left standing in a chamber of ether, or in water for a few days, and then subjected to like treatment, gives much more hypoxanthine. It is concluded that hypoxanthine is in a combined state in fresh meat and is liberated on standing raw, but that heating almost stops this action.
On the Unification of Soil Analysis: E. W. HuLGARD.

This paper, while insisting strongly upon the practical need of soil analysis for the determination of permanent soil values, deplores the lack of uniformity in the method of preparing the soil exrract, whereby comparisons are rendered difficult or impossible, and an enormous amount of work is wasted. In view of the hopelessness of any international agreement upon arbitrary prescriptions, the adoption of a natural limit of extraction, by the action of strong acids-preferably hydrochloric-is recommended; according to the author's experience, the results of such analyses lend themselves to practical interpretation at least as readily as those by any other method.

Quantitative Chemical Analysis of Animal Tissue -V., Estimation of Chlorine: W. KocH.

The estimation of chlorine, either by analysis of the total ash or by direct water extraction in tissues rich in lipoids such as the brain or liver, can hardly be said to yield results of any degree of accuracy. In the ash the chlorides are often replaced by sulphates or phosphates derived from the burning of organic combinations of these elements. A watery extract of a tissue like the brain can only be filtered with the greatest diffculty and the complete extraction would be almost impossible.

In connection with the methods previously outlined under the above general title it was found that the chlorides all pass into the fraction 2 or the alcohol soluble fraction. By precipitating the lipoids in this fraction without chloroform and with nitric instead of hydrochloric acid a solution is obtained in which the chlorides can be titrated direct by Volhard's method. The estimation of chlorine can be thus combined with that of any other tissue constituent described in these methods. Some results obtained on the brain are given below:

\begin{tabular}{|c|c|c|c|c|}
\hline & \multicolumn{2}{|c|}{ Whole Brain } & \multicolumn{2}{|c|}{ Corpus!Callosum } \\
\hline & $\begin{array}{l}\text { In per } \\
\text { cent. of } \\
\text { moist } \\
\text { tissue }\end{array}$ & $\begin{array}{l}\text { In per } \\
\text { cent. of } \\
\text { dry } \\
\text { tissue }\end{array}$ & $\begin{array}{l}\text { In per } \\
\text { cent. of } \\
\text { moist } \\
\text { tissue }\end{array}$ & $\begin{array}{l}\text { In per } \\
\text { cent. of } \\
\text { dry } \\
\text { tissue }\end{array}$ \\
\hline Case 74 & 0.20 & 0.89 & & \\
\hline Case 75 & 0.16 & 0.71 & 0.15 & 0.48 \\
\hline
\end{tabular}

A Convenient Drying Oven: M. M. MacLean.

An oven for small laboratories made of two thicknesses of thin sheet iron with asbestos board between; heated by incandescent lamps, the temperature controlled very accurately by thermostat device. 
The Constituents of the Wax of Candelilla or Mexican Wax Plant: G. S. FraPs and J. B. RATHER.

A hydrocarbon was isolated from this substance, melting at $68^{\circ}$, not very soluble in cold ether or chloroform, soluble in hot, difficultly soluble in hot or cold alcohol. It is probably hentriocontane, $\mathrm{C}_{31} \mathrm{H}_{64}$, which has also been found in beeswax. Two other bodies were separated but have not yet been identified.

A Polariscopic Method for the Determination of Malic Acid and its Application in Cane and Maple Products: P. A. YoDER.

Making use of the fact that uranyl compounds cause a manifold increase in the optical activity of active dicarboxylic hydroxy-acids, the author has developed from extensive original data a method of estimating malic acid in solutions which may at the same time contain a wide range of other substances. The rotatory power of the uranium-malic-acid compound was found, for a 1 per cent. solution to be $-29.7^{\circ}$ Ventzke for white light and - 28.9 $9^{\circ}$ Ventzke for yellow light, while that of the malic acid itself in a 1 per cent. solution is -0.13 . Letting $P=$ the polarization before and $P^{\prime}$ that after the addition of uranyl acetate, $t=$ the temperature $\mathrm{C}$. and $L=$ the length of the polarization tube in dem., then, with yellow light

per cent. mallic acid $=$

$$
\frac{\left(P^{\prime}-P\right) \times[1+0.001(t-20)]}{-28.8 \times \frac{1}{2} L} .
$$

For white light substitute 29.6 for 28.8 in the formula.

Strong mineral acids in the free state or an excess of alkali interfere. Any degree of acidity (concentration of $\mathrm{H}$ ions) through the range between the two standards: (1) one third $N$ acetic acid, and (2) one third $N$ acetic acid with one fourth of it neutralized with $\mathrm{KOH}$, is favorable for maximum activity. This degree of acidity may be established in a solution by adding acetic acid or $\mathrm{KOH}$ until, with methyl orange as indicator, a shade is produced between the shades caused by the above two standards. Or the maximum rotatory effect is found by successive additions of acetic acid or $\mathrm{KOH}$ to the solution in the polarization tube and trial polarizations after each addition. A tubulated polariscope tube of special construction is suggested for these trials. At least 1.25 atom $U$ should be present for each molecule malic acid, and more in the presence of certain other organic acids. To sepa- rate malic acid from syrups, either precipitate with lead acetate and 3.6 volumes 95 per cent. alcohol for each volume of water, liberating the acid from the lead by $\mathrm{H}_{2} \mathrm{~S}$, or precipitate with barium acetate and 14 volumes 95 per cent. alcohol for each volume of water, dissolving then the barium malate in water to separate from the sulphate, phosphate, etc. Add to the barium malate solution acetic acid to get the maximum rotatory activity.

Two cane syrups had 0.02 and 0.04 per cent., respectively, and four samples of maple syrup had $0.49,0.32,0.26$ and 0.51 , respectively, of malic acid.

By a similar method for d-tartaric acid, polarizing with white light and at $27.5^{\circ} \mathrm{C}$.,

$$
\text { per cent. tartaric acid }=\frac{P^{\prime}-P}{25.16 \times \frac{1}{2} L} .
$$

For a mixture of tartaric and malic acids, if $n=$ total c.c. $\mathrm{N}$ alkali required to neutralize 100 c.c. of the solution, and $m=$ change in polarization in degrees Ventzke in a $20 \mathrm{~cm}$. tube with white light and at $27.5^{\circ} \mathrm{C}$., then

per cent. malic acid $=0.03287 n-0.01741 m$, and

per cent. tartaric acid $=0.03824 n+0.01949 m$.

Notes on the Determination of Acids in Sugar. cane Juice: P. A. YoDER.

Data are collected upon which to base methods of separating, estimating and identifying organic plant acids. By a simple form of apparatus improvised by the author, the succinic, aconitic and lactic acids are readily extracted by ether from their water solutions. The malic, citric and tartaric acids go over into the extract very slowly. Solubility or precipitability tests were made with the calcium and certain other salts of these acids. As a means of identifying citric acid, Denige's acetone dicarboxylic acid reaction is very delicate for citric acid, giving, however, the same results with the preparations of aconitic acid that were on hand.

In a sample of cane juice partly analyzed were found, per 100 c.c. fresh juice, $0.00314 \mathrm{~g}$. phosphoric, 0.00004 g. oxalic, 0.00077 g. malic and about $0.05 \mathrm{~g}$. aconitic acids. Sulphuric acid was also present. Tartaric, succinic and citric acids were absent.

Biochemical and Toxicological Studies upon a Number of Species of Penicillium: C. L. ALsBERG and O. F. BLACK.

The moulds of the genus Penicillium have been 
regarded as the chief organisms which spoil corn in such a way as to cause it to produce pellagra when consumed by badly nourished, wretchedly poor peasantry living under poor hygienic conditions. It has been reported by a number of Italian investigators that these moulds produce toxic substances, and it is believed that these substances are phenol acids. This belief is based not upon the isolation and identification of these substances, but upon the fact that extracts of the cultures gave red or violet colors with ferric chloride. However, not all investigators have been able to obtain toxic extracts from cultures, or extracts giving a positive reaction with ferric chloride. Hence, the whole question whether or not Penicillium produces toxins when growing upon corn, and whether or not this organism has anything to do with the production of pellagra, is still unsettled.

It has occurred to the authors that the discrepancy in the results obtained by various investigators may possibly be due to the fact that the organisms which each investigator studied may not have been identical. Very recently there has appeared from the department of agriculture a publication by Thom, ${ }^{x}$ in which for the first time the fungi of this genus have been adequately studied from the systematic point of view. It is therefore now possible to investigate each species separately. The authors are engaged upon the investigation of the biochemistry of different species of Penicillium which have been obtained from Thom, and which Dr. Erwin F. Smith has been kind enough to grow. Great differences have been found in the products of five of the species investigated so far. Of these five but one gives a positive ferric chloride reaction, and the toxicity of the extracts varies greatly for the different species. The authors are engaged upon a detailed study of the products produced by these organisms, of the relative toxicity, and of the nature of the substance which is responsible for the ferric chloride reaction. It is hoped that this preliminary report may soon be followed by a detailed publication in which these other points will be definitely cleared up.

Field Tests with Plant Foods, Materials and Results: H. A. Huston.

In the winter wheat section of the United States, commercial plant foods are very profitably used, while the reports of most of the plot tests

${ }^{1}$ U. S. Dept. Agri., Bureau Animal Industry Bull. No. 118. at experiment stations indicate that they are unprofitable. Some reasons for this apparent conflict are pointed out, special reference being made to necessity of using materials free from substances like the gypsum contained in acid phosphate and the sodium in nitrate of soda capable of producing indirect effects, to the desirability of using suitable methods of application, proper amounts of materials, and reasonable interpretation of results.

The Negative Infuence of Soils upon the Nitrogen Content of Wheat: G. W. SHAw.

In connection with another research the analytical results of which have been published in Bulletin No. 128 of the bureau of chemistry, department of agriculture, experiments have been conducted to differentiate between the climate and soil factor upon the protein content of wheat.

In 1907 until the present season the writer has undertaken to neutralize one of these factors, viz., climate, by securing from Hays, Kans., a plat of soil $6 \times 3 \times 3$ feet which for a long period had produced high protein wheat, and the preceding season produced wheat carrying 20.06 per cent. of total protein. A quantity of this wheat was also obtained at the same time.

The soil was removed from its original position in six-inch layers and brought to California, where it was placed alongside of a plat of California soil prepared in a similar manner, each of the holes having been first lined, except at the bottom, by a loose cement lining.

On one end of each of these plats was grown in 1907-8 wheat from the original high-protein wheat from Kansas, and on the ather end a handselected low-protein durum wheat. By this soil transfer it was intended to neutralize the effect of climate and to have as a variable factor only the soil.

In physical character each of the soils would be classed as silt loams. Chemically there was essentially no difference in the top foot, which held particularly true in the essential elements of plant food. In the other two feet the main difference lay in the nitrogen content, this being the greater in the California soil, thus giving it a slight advantage in this respect. The detailed analyses are presented in tabular form.

In the first season the grain produced from the low-protein original increased by about 4.5 per cent. on each of the two plats, there being a difference of only 0.07 per cent. total protein 
between the soils under comparison, thus indicating a very marked seasonal influence toward the formation of high protein grain, and at the same time that the influence of the soil was practically nil.

In the case of the grain produced from the high-protein original from Kansas showing 20.06 per cent. total protein, there was a decrease on each of the soil plats by about 2 per cent., but as between the soils there was a difference of but 0.27 per cent. In each case the slight difference was in favor of the California soil, but the difference was altogether too small to be attributed with any certainty to inherent difference in soil composition.

In 1908-9 a similar condition was again shown on these plats, leading to like conclusions.

The alcohol-soluble nitrogen also points in this direction, for the difference in this component of the grain from the two plats is only 0.06 per cent., this being in favor of the California soil. In the matter of salt-soluble nitrogen we find such small differences as do occur are in favor of the Kansas soil.

Thus we have a soil which in Kansas has for many years produced a very high protein grain, when brought to California and placed under the same conditions as the home soil, producing grain of the same protein content as the native soil.

These experiments are being carried further to endeavor to ascertain which of several climatic factors may have the predominating influence.

The following papers were also presented:

The Relation of Carbon Dioxide Excretion to Body Weight: G. O. HigLeY.

The Carbon Dioxide Excretion as Modified by Barometric Changes: G. O. HIGLEY.

The Physiological Action of Thallium Salts as shown by the Nitrogenous Metabolism: R. E. SWAIN.

The Utilization of Starch Introduced Directiy into the Circulation: R. E. SwaIN.

The Destruction of Invertase Solutions in the Absence of a Preservative: F. C. Cook.

The Destruction of Invertase Solutions by Shaking and by the Electric Current: F. C. Coor.

Résumé of the Work of the California State Food and Drug Laboratory: M. E. JAFFA.

Testing for Saccharin: LouIs H. JAcksoN.

Citral in Lemon Oils and Extracts: R. S. HILTNER.

The Composition of Rice as Affected by Fertilization: W. P. Kelley.
DIVISION OF INDUSTRIAL CHEMISTS AND CHEMICAL ENGINEERS

A special feature of the program of this division was the symposium on smelter smoke, which was full of interest. Three important papers had been prepared for this occasion:

The Smoke Problem and the Community: CHas. BASKERVILLE.

The Neutralization and Filtration of Smelter smoke: W. C. EBaugh.

The Electrical Precipitation of Suspended Matter: F. G. Cottrell.

The Smoke Problem and the Community: Charles Baskerville.

In this paper, which opened the symposium on "Smelter Fumes," the smoke problem is discussed historically, and from sociological, legal and economic view points. The methods which have been suggested for smoke abatement and the use of waste-reclaiming devices; the occurrence of sulphur dioxide in city air; the effects of sulphur dioxide and other waste gases; and the work of the expert in cases arising from the emission of noxious gases, are considered in their various phases; but the larger portion of the paper deals with the legal status of the smoke problem, and various recommendations with respect to legislation, jurisdiction and administration are made. From a study of the foreign legislation relating to noxious emissions, and the practicability of remedies in general, it is concluded that "the main solution of the 'fume question' and 'air pollution' would seem to be in the enforced use of waste-reclaiming devices, by the enactment of a federal law regulating the amounts of waste gases to be permitted to pass into the air."

The Effect of Varying Amounts of Litharge in the Fire Assay for Silver: KenNeTH WILLIams.

In seeking to account for variable results obtained in the crucible assay for silver on oxidized lead ores, containing only traces of such impurities as copper, zinc and arsenic, a series of assays were run, using fluxes containing varying amounts of litharge in excess of the amount necessary to furnish a lead button of convenient size for cupellation.

It was found that with increased amounts of excess litharge, lower silver values were obtained.

The amount of variation was from one to four tenths of an ounce per ton on ores carrying from twenty-five to fifty ounces of silver.

Problems in Chemical Industry: JoHN T. BAKER, Phillipsburg, N. J.

In this paper the author pointed out that the 
number and complexity of the factors involved in chemical operations are so great that many operations are still carried on under the rule of thumb guidance and have not been reduced to a science. On the other hand, the trained scientific man is very prone to believe that the matter with which he deals will follow the laws which he has learned, and for this reason he often overlooks valuable facts which the untrained observer sees. The untrained observer ignores laws and systems, tries any suggestion that comes along, and while much valuable time and labor may be lost, the loss is fully compensated by a few valuable successes. The investigator who is successful follows a mean between these paths. A number of practical illustrations of these principles were given.

Factors Affecting the Electrolytic Method for the Determination of Copper in Ores: W. C. BASDALE and W. H. Creuss.

The paper discusses and gives the results of experimental data relating to the rate of precipitation of copper, as affected by the form of electrodes used, the amperage, the concentration of the solution and the kind and nature of the acid present. It is also shown that the presence of salts of ferric iron merely delays precipitation where no $\mathrm{NO}_{3}$ ions are present, but where the latter are present and the amount of iron is large, complete precipitation is sometimes impossible. This is attributed to the formation of nitrous acid, which has a strong solvent action on metallic copper. The difficulty can be avoided by the addition of urea to the solution.

The Electrolytic Determination of Zinc in Ores: GEo. KemMERER.

Recent workers obtained high results using an electrolyte containing a small excess of sodium hydroxide. These results were confirmed with -similar electrolytes. With 20 to 25 grams of sodium hydroxide per 100 c.c. the results were not high and all the zinc was precipitated. A nickel gauze cathode and rotating anode were used with a current N.D.10p 3.1 amperes.

When applied to ores the sulphide obtained by the "modified Waring" method contained iron. This was eliminated by adding four to five drops of concentrated hydrochloric acid to the neutral solution where the Waring method calls for six drops of one-to-six acid.

This sulphide dissolved in hydrochloric acid, evaporated with 2 c.c. of sulphuric acid to dense fumes was dissolved in 100 c.c. of water, 25 grams of sodium hydroxide added and electrolyzed. The results varied less than 0.3 per cent. and agree well with the volumetric results on standard ores.

The titles of other papers presented are as follows:

Scum or Efflorescence on Brick: A. F. GREAVESWALKER.

The Composition of Solids Precipitated from the Atmosphere during a "Salt Storm": W. C. Ebaugh.

The Scientific Use of Crude Petroleum as a Source of Power: LEON LABONDE.

The Cuban Hedge Cactus; a Proposed Source of Crude Rubber: Chas. P. Fox.

Ficus elastica in Florida: CHAs. P. Fox.

Some Recent Advances in Textile Chemistry: J. M. MatThews.

Alloys of Nickel and Cobalt with the Metals of the Chromium Group: Euwood Haynes.

Rust as an Accelerator in the Corrosion of Iron and steel: W. D. RICHARDson.

Rapid Estimation of Available Calcium Oxide in Lime Used in Cyanide Work: L. W. BAHNEY.

DIVISION OF PHYSICAL AND INORGANIC CHEMISTRY Stratification in Suspensions: F. K. CAMERON and E. E. FREE.

When a little very fine clay or similar material is added to water and allowed to settle, there are usually formed a number of strata differing in clay content and which are separated by more or less sharp surfaces. These surfaces move slowly downward with the settling of the material. Previous work on this phenomenon is largely worthless because of the disturbing effects of convection currents in the medium. The authors have constructed a double-walled cabinet inside which temperature changes are very slow and uniform and by the use of which these convection currents can be almost entirely avoided. Using this cabinet, the rates of fall of the strata of a number of clay-water mixtures have been carefully measured. The rate of fall of each stratum is constant, but a stratum may divide into two, one of which falls faster, the other more slowly, than the original. This division may be several times repeated. The number of strata formed in any particular system and their rates of fall seem to be determined partly by the nature of the system and partly by other, and apparently accidental, factors which are not yet understood.

The Consolidation of Kaolin Precipitates: F. K. Cameron and E. H. Free.

When mixtures of powdered kaolin with from 
ten to one hundred times its weight of water are shaken and allowed to stand in tall jars or cylinders, there develops almost at once a sharp surface between the falling kaolin and the clear solution above. This surface sinks as the kaolin consolidates and its rate of fall represents the rate of consolidation of the kaolin. The curve representing the relation between the position of this surface (or the apparent volume of the kaolin) and the time of standing has been found to be an hyperbola, the central portion of which may be represented quite well by an exponential equation analogous in form to that of the mass law. On both ends of the curve the fall is slower than required by this equation. The reasons for these retardations are being more fully investigated.

The Action of Potassium Hydroxide upon Kaolin

Suspensions: F. K. CAMERON and E. E. FREE.

The authors have studied the action of varied concentrations of potassium hydroxide on the degree of flocculation (and hence of the rate of settling) of suspensions of one gram of finely powdered kaolin in 100 c.c. of water. In very dilute solutions there is no noticeable action. At a concentration of about 0.015 gram $\mathrm{KOH}$ per liter of solution there begins suddenly a strong deflocculation or decrease in the degree of flocculation. At about 1 gram per liter the degree of flocculation begins to increase' slowly and at about 4.5 grams per liter the degree of flocculation is the same as in pure water. This increase continues with increase in the $\mathrm{KOH}$ content and at about 10 grams per liter the degree of flocculation reaches a maximum after which it very slowly decreases. This final decrease is probably more apparent than real and due to the direct effect of the increased viscosity and density of the solution on the rate of settling.

Heats of Reaction in Non-aqueous Solvents (preliminary paper) : J. Howard Mathews.

The first reaction chosen for study was the exact neutralization of 1 molecule of pyridine by 1 molecule of acetic acid. The product of this reaction is a liquid, and remains in solution in all of the solvents used. The heat evolved by this reaction in ten different solvents was measured by a slight modification of the adiabatic method devised by Richards and Rowe ${ }^{2}$ for measuring specific heats of liquids. The quantity of heat evolved was found to depend on the solvent used. In solvents where side reactions were impossible the values obtained were of the same order as the

${ }^{2}$ Z. physik. Chem., 64, 187, 1908. value obtained where no solvent was used, but the differences were much greater than the experimental error, which was certainly less than 0.1 per cent. The study is to be continued.

A Suggestion to Instructors in Quantitative Analysis: W. C. Ebaugh.

Material for use of students in quantitative analysis can frequently be obtained from commercial laboratories in the neighborhood of a technical school, and will save much time and trouble as well as expense to teachers. The portions of samples that have been analyzed, or reserve samples that have been prepared for the use of an umpire, but not needed for that purpose, are issued to students, and as the analysis results used for settlement are furnished by the laboratories that prepared the samples the work of the students can be checked accurately. It has been found that students take a greater interest in analyzing such samples than in working with material that has not been in commercial use.

A Reported Occurrence of Native Iron: W. C. Ebaugh.

A sample of metal, thought to be platinum, was sent to the University of Utah by Cecelia M. Gettings, of Moab, Utah. Later a second sample from the same source was received, and an affidavit accompanied it declaring that the material had been found in a certain mining (placer) claim in the La Sal Mountains east of Moab. The material proved to be magnetic, was malleable, had a specific gravity of 7.82 , and upon analysis yielded

$$
\begin{aligned}
& \text { Carbon .......... } 0.08 \text { per cent. } \\
& \text { Silicon } \ldots \ldots \ldots \ldots \ldots \ldots .20 \text { per cent. } \\
& \text { Phosphorus ......... } 0.0003 \text { per cent. } \\
& \text { Sulphur .......... undetermined } \\
& \text { Manganese .......... traces } \\
& \text { Nickel ............ absent } \\
& \text { Cobalt ........... absent } \\
& \text { Aluminum .......... absent } \\
& \text { Chromium .......... absent }
\end{aligned}
$$

There seemed to be no question in the minds of the men who discovered the metal that it was of native occurrence, and could not have come into the deposit from tools or other articles made by man.

Equilibrium in the System $K I, I$ and Aqueous Alcohol: C. L. Parsons and H. P. Corliss.

Equilibrium experiments carried out in detail show positively that no solid polyiodides of potassium exist at $25^{\circ}$. The solubility curves were 
traced throughout their full length and the invariant point found when both potassium iodide and iodine existed together as solid phases in presence of their mutually saturated solutions. 'The curve was traced for both 60 and 40 per cent. alcohol.

The Solubility of Barium Nitrate in Solutions of Barium Hydroxide: C. L. Pansons and H. P. Conson.

The solubility curves were traced for barium nitrate in all concentrations of barium hydroxide and likewise for barium hydroxide in all concentrations of barium nitrate. The solubility of each was shown to be increased by the presence of the other. It was also shown that no solid basic nitrate of barium can exist at $25^{\circ}$.

The Solubility of Strontium Nitrate in Solutions of Strontium Hydroxide: C. L. PARsons and C. L. Perkins.

Strontium nitrate and hydroxide were found to be strictly analogous to barium as described in preceding abstract.

Basic Nitrates of Ytrium: CHAS. JAMES and L. A. Pratr.

Equilibrium experiments show that only one basic nitrate of yttrium exists, viz., $3 \mathrm{Y}_{2} \mathrm{O}_{5} \cdot 4 \mathrm{~N}_{2} \mathrm{O}_{5}$. $20 \mathrm{H}_{2} \mathrm{O}$. The solubility curves are also shown.

Comparative Analyses of Water from Great Salt

Lake: W. C. Ebaugh and Wallace MacfarI.ANE.

From 1900 until 1904 fears were expressed that the Great Salt Lake was doomed to extinction, as a continuous recession of the shore line took place. Since that time there has been a rise in the level of the lake and during the year just ended new fears have arisen-fears that large engineering works like the Lucin cut off of the Southern Pacific and the roadbed of the Western Pacific Railroad would have to be abandoned. A succession of years with abnormally high rainfall is responsible for the condition now existing.

Analyses of the water since 1850 are collated and many new analyses given. These show the density to have been as low as 1.102 in 1873 and as high as 1.2206 in 1903 ; total solids varying from 13.42 per cent. to 27.72 per cent. The figures for February, 1910, being specific gravity 1.1331 and total solids 17.681 per cent. Complete analyses of the water for the years 1903, 1904, 1907, 1909 and 1910 are also reported.

Improvements in Molecular Weight Determinations by the Boiling Point Method: L. P. ShIPLeY and J. O. Zieboltz.
The thermometer is placed above the liquid and the boiling of the latter is made to pump a portion of it over the bulb in a thin film analogous to the reflux current in the ordinary arrangement for determining boiling points of pure liquids. Errors from superheating are thus practically eliminated and steadiness of thermometer readings increased at least tenfold besides simplifying the apparatus now in general use.

Interrelations of the Carbide and Nitride of Magnesium: F. G. CotTrELL.

A mixture of anhydrous liquid ammonia and acetylene at room temperature attacks metallic magnesium rapidly, forming clear colorless tetrahedra of $\mathrm{MgC}_{2} \cdot \mathrm{C}_{2} \mathrm{H}_{2} \cdot 5 \mathrm{NH}_{3}$, which lose one and a half molecules of ammonia sharply at $2^{\circ} \mathrm{U}$. and atmospheric pressure. Above $60^{\circ} \mathrm{C}$. they give off a mixture of acetylene and ammonia, leaving a little carbide and much nitride of magnesium. At low temperature in vacuo, on the other hand, the essentially pure carbide, previously unknown, may be obtained. The carbide, a white powder, begins to decompose into its elements at 425 to $450^{\circ} \mathrm{C}$. Metallic magnesium dissolves slightly in liquid ammonia with faint blue color, and even at room temperature slowly forms the amide and hydrogen.

Apparatus for Determining Vapor Pressures of Slightly Volatile Solids: H. V. WELCH.

The method depends upon determining the amount of material carried off in a known volume of air or other gas passed through a tube of the solid in a thermostat. The latter is of the boiling liquid type, temperature regulation being effected through automatic electrical control of a valve leading to a vacuum pump. Arsenic trioxide and similar solids are being investigated at present.

Preparation of Pure Anhydrous Ethyl Alcohol:

E. C. McKknvy.

The demand for alcoholometric density tables of greater precision than the various discordant ones in use at present has led to the repetition at the bureau of standards of the experimental work upon which such tables are based. Absolute alcohol was prepared by using several different dehydrating agents including lime, calcium and aluminium amalgam. The density results obtained were very concordant and point to a value for the density of $0.78506 \pm 0.00001$ at $25^{\circ} / 4^{\circ}$ which is slightly lower than Mendeleef's corrected value. Acetaldehyde was found to increase the density while ethyl ether and dissolved air had the opposite effect. 
The Rapid Determination of Silver, Copper, Cadmium and Bismuth by Means of the Mercury Cathode and Stationary Anode: R. C. BENNER. Work which has béen recently completed indicates that the rapid electrolytic determination of many metals can be accomplished by means of stationary electrodes in nearly the same time as with the more complex forms of apparatus.

In order to avoid loss by boiling of the solution when high currents are used, tall electrodes similar to those utilized by Smith were constructed. Standard solutions of copper nitrate, silver nitrate, cadmium sulphate and bismuth nitrate were prepared from chemically pure materials. 'T'he electrolysis was carried out in case of each metal in the presence of nitric acid, and sulphuric acid, with a current varying from three to four amperes. The solution always had a volume of twenty cubic centimeters. The results were as accurate as could be desired and as good as those obtained by Smith by means of the rotating anode and mercury cathode. It is possible to precipitate 0.3833 gram of copper in twenty minutes, 0.2856 gram of silver in ten minutes, 0.743 gram of cadmium in ten minutes and 0.4650 gram of bismuth in twenty-five minutes.

The Atomic Weight of Tantalum: Clarence W. BALKE.

Tantalum oxide was prepared from purified potassium fluotantalate. It was converted into tantalum pentachloride. The latter, weighed in quartz bulbs with great care to avoid contact with moist air, was hydrolyzed in portions weighing from six to eighteen grams and the weight of tantalum oxide determined. Eight determinations gave values for the atomic weight of tantalum from 181.46 to 181.55 with a mean of 181.52, which is one half of a unit higher than the value given in the International Table of Atomic Weights.

Apparatus for the Determination of Arsenic: OTIS D. SwETT.

This is a self-contained apparatus, disposed vertically within the limits of its base, which has a diameter of $11 \mathrm{~cm}$, and having a height of $44 \mathrm{~cm}$. The reaction chamber is surrounded by a jacket through which hot or cold water may be passed as a temperature control. The charge is admitted through a tube, sealed into a stopper ground into the neck of the reaction chamber, and extending to near the bottom of the latter, where it terminates in a gas trap bend. The arsine enters a tube, sealed into the said stopper, passes through a drying tube, and into a combus- tion tube, fitted by means of a flat connection with spring clip to the exit from the drying tube, and heated electrically. Arsenic mirrors are formed and compared with standards. The combustion tube may be replaced by a suitably bent tube with a horizontal limb carrying a sensitized paper.

Potassium Ammonoplumbite and Potassium Ammonocadmiate: EDwaRd C. FRANKLIN and George S. Bohart.

Franklin and his coworkers have shown that liquid ammonia is an electrolytic solvent which exhibits many striking similarities to the more familiar solvent water. In particular they have shown that just as the ordinary oxygen or "hydro" acids, bases and salts may be said to constitute a water system, so there exists a large number of nitrogen compounds which similarly constitute an ammonia system of acids, bases and salts.

The authors now show that just as potassium hydroxide, a water or hydrobase, in aqueous solution, reacts with lead hydroxide, an amphoteric hydroxide, to form the hydrosalt, potassium plumbite, in accordance with the equation,

$$
2 \mathrm{KOH}+\mathrm{Pb}(\mathrm{OH})_{3}=\mathrm{Pb}(\mathrm{OK})_{2}+\mathrm{H}_{2} \mathrm{O},
$$

so potassium amide, an ammonobase, in solution in liquid ammonia, acts upon lead imide, an amphoteric imide, to form the ammonosalt, potassium ammonoplumbite in accordance with the equation,

$$
\mathrm{KNH}_{2}+\mathrm{PbNH}=\mathrm{PbNK}+\mathrm{NH}_{3} .
$$

The salt separates from concentrated solutions in the form of beautiful, colorless, transparent crystals of the formula, $\mathrm{PbNK} \cdot 3 \mathrm{NH}_{3}$.

A potassium ammonocadmiate of the formula, $\mathrm{Cd}(\mathrm{NHK})_{2} \cdot 2 \mathrm{NH}_{3}$, has been prepared by the action of an excess of a solution of potassium amide on cadmium iodide suspended in liquid ammonia.

Cuprous Nitrate: WM. H. SLouN.

When metallic copper is digested with a solution of cupric nitrate in liquid ammonia and cuprous nitrate is formed and may be isolated in the form of colorless crystals by the evaporation of the solvent. The composition of the crystalline salt is represented by the formula, $\mathrm{CuNO}_{3} .4 \mathrm{NH}_{3}$.

The Viscosity of Ammonia, Methylamine and Sulphur Dioxide and Certain of their Solutions: F. F. Fitzgerald.

In agreement with the hypothesis that the more fluid electrolytic solvents give solutions which exhibit high maximum molecular conductivities 
the author has found these solvents to possess a high degree of fluidity.

The Electrical Conductivity of Solutions in Methylamine and Ethylamine: F. F. FrTzGERALD.

The author has measured the conductivity of a number of salts in these solvents through a considerable range of concentrations and at temperatures ranging from $+15^{\circ}$ to $-33^{\circ}$. The maximum and minimum of the molecular conductivity curve, first noted by Franklin and Gibbs, have been found to characterize all the solutions studied.

The Charges of Ions in Electrolysis: FERNANDo SANFORD.

Since no case is known where an electrolytic ion gives off a positive charge to an electrode, we have no way of measuring directly the positive charge on such an ion. If the ions are assumed to have very short free paths, they will move with accelerated velocities. If this acceleration were uniform, their relative ionic charges could be computed from the equation force $=$ mass $\times$ acceleration, since in a given electric field the force acting upon an ion is proportional to its charge.

The following table shows the relative charges of three groups of ions calculated in this way:

\begin{tabular}{|c|c|c|c|c|}
\hline 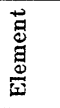 & 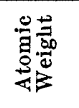 & 总 & 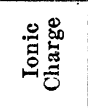 & Ratio of Charges \\
\hline $\mathrm{Cs}$ & 133 & 78.8 & 10480 & $\mathrm{Cs} / \mathrm{I}=1.07$ \\
\hline $\mathrm{Rb}$ & 85.5 & 78.6 & 6720 & $\mathrm{Rb} / \mathrm{Br}=1.07$ \\
\hline $\mathrm{K}$ & 39 & 75.5 & 2945 & $\mathrm{~K} / \mathrm{Cl}=1.09$ \\
\hline $\mathrm{Na}$ & 23 & 52.6 & 1210 & $\mathrm{Na} / \mathrm{F}=1.17$ \\
\hline $\mathrm{Li}$ & 7 & 42.6 & 298 & \\
\hline $\mathrm{H}$ & 1 & 365 & 365 . & \\
\hline I & 127 & 77 & 9779 & $\mathrm{I} / \mathrm{Ba}=1.04$ \\
\hline $\mathrm{Br}$ & 80 & 78.1 & 6248 & $\mathrm{Br} / \mathrm{Sr}-1.06$ \\
\hline $\mathrm{Cl}$ & 35.5 & 75.1 & 2666 & $\mathrm{Cl} / \mathrm{Ca}=1.07$ \\
\hline $\mathrm{F}$ & 19 & 54.4 & 1034 & $\mathrm{~F} / \mathrm{Mg}=1.02$ \\
\hline $\mathrm{Ba}$ & 137.4 & 68 & 9343 & $\mathrm{Cs} / \mathrm{Ba}=1.12$ \\
\hline $\mathrm{Sr}$ & 87.6 & 67 & 5869 & $\mathrm{Rb} / \mathrm{Sr}=1.14$ \\
\hline $\mathrm{Ca}$ & 40.1 & 66 & 2646 & $\mathrm{~K} / \mathrm{Ca}=1.11$ \\
\hline $\mathrm{Mg}$ & 24.3 & 46 & 1018 & $\mathrm{Na} / \mathrm{Mg}=1.18$ \\
\hline
\end{tabular}

Titles of other papers of which no abstracts have been received follow:

Further Studies on the Action of Ammonia upon Ethyl-phospho-platino-chloride: CHAS. H. HERTY and HAMDEN HrrL.

The Temperatures of the Carborundum Furnaces: WILDER D. BANCROFT.
Salvaging sulphated Storage Cells: WILDER D. BANCROFT.

The Silver Coulometer: G. D. BuCKNer and G. A. HULETT.

Occlusions in Electrolytic silver: J. S. LAIRD and G. A. HuletT:

An Exact. Electrolytic Method for Determining some Metals: W. L. Perdue and G. A. Huletr. Cadmium Sulphate and the Atomic Weight of Cadmium: W. L. Perdue and G. A. Hulert.

A Common Thermometric Error in Determining Boiling Points under Reduced Pressure: AlexANDER SMITH.

A Convenient Form of Vapor Density Apparatus: Alan W. C. Menzies.

The Systems, Lime-water-sugar and Lime-waterglycerine at $25^{\circ}$ C.: F. K. CAMERON and H. E. Patten.

Phosphates of Lime IV.: F. K. Cameron and J. M. BELL.

The Influence of Organic Liquids upon the Interaction of Hydrogen Sulphide and Sulphur Dioxide: David KLEIN.

Concerning the Molecular Weight of Sulphur Vapor: O. F. STAFFORD.

A Rotating Graphite Anode: J. W. TurRentine. Behavior of Certain Hydrazine Salts in Liquid Ammonia: A. W. Browne and A. E. HouleHAN.

Electrolysis of Solutions of Potassium Amide and of Ammonium Trinitride in Liquid Ammonia: A. W. Browne and M. E. Holmes.

Electrolytic Corrosion of Various Metallic Anodes in a Solution of Ammonium Trinitride in Liquid Ammonia: A. W. Browne, M. E. Holmes and J. S. KING, JR.

The Examination of Ethyl Ether: CHaRLes BAskerville and W. A. Hamor. (a) A Study of the Tests for Odor, Residue, Acidity and Sulphur Compounds in Ethyl Ether. (b) The Tests for the Presence of Water and Alcohol in Ethyl Ether. (c) On the Changes Occurring in Stored Ether and on the Existence of Ethenol in Ethyl Ether. (d) The Tests for the Presence of Peroxides and Acetaldehyde in Ethyl Ether. (e) On some New Tests for the Detection of Peroxides in Ethyl Ether. ( $f$ ) The Examination of Ethyl Ether intended for Anesthetic and Reagent Purposes; the Degrees of Purity of American Ethers, and Recommendations for the Standardization of Anesthetic Ether. 
Mechanical Stimulus to Crystallization: S. W. Young.

Zinc Ammonium Sulphate: EloIse JAMeson.

Conductivity of some Solutions in Ammoniawater Mixtures: WM. H. SLoAN.

DIVISION OF ORGANIC CHEMISTRY
Stilbazoles in the Quinazoline Group: M. T. Bogert and G. D. BeAL.

2-methyl-4-quinazolones and 3-amino-4-quinazolones both condense with aromatic aldehydes, the condensation taking place with either the methyl or the amino group, or both. The products obtained by the condensation with the methyl group are of stilbazole type, those with the amino group are somewhat analogous to the Schiff bases. The aldehydes used were benzaldehyde, salicylaldehyde, vanillin and cinnamic aldehyde. Very strangely, no good condensations were obtained with citral or with furfural. The aldehydes condense first with the amino group and then with the methyl group. When the products are treated with strong hydrochloric acid the aldehyde group is easily broken away from the nitrogen but not from the carbon union. Various derivatives were prepared and studied.

Isocampholactone: W. A. NoYes and A. W. HoMBERGER.

When isocampholactone is treated on the waterbath with nitric acid (1.27) a nitroisocampholactone, $\mathrm{C}_{9} \mathrm{H}_{13} \mathrm{O}_{4} \mathrm{~N}$, is formed. This gives an amine and a hydroxylamino compound by reduction with tin and hydrochloric acid or zinc and acetic acid, respectively. The nitrolactone gives an amide, $\mathrm{C}_{6} \mathrm{H}_{10} \mathrm{~N}_{2} \mathrm{O}_{3}$, on treatment with ammonia and an acid, $\mathrm{C}_{6} \mathrm{H}_{9} \mathrm{NO}_{4}$, on treatment with sodium hydroxide. At the same time with the nitroisocampholactone a small amount of a lactone acid, $\mathrm{C}_{9} \mathrm{H}_{14} \mathrm{O}_{4}$, was also formed. From this an amide, $\mathrm{C}_{9} \mathrm{H}_{15} \mathrm{NO}_{4}$, was prepared.

Separation of aa'-dimethyladipic Acid into its Optical Isomers and Synthesis of Laurolene: W. A. Noyes and L. P. KYriakides.

Although there seems to be no reason, theoretically, why dialkylsuccinic acids and other acids of a similar type should not be capable of separation into their optical isomers, all attempts to effect such a separation have, heretofore, been unsuccessful. Lean and some others have gone so far as to suppose that there must be some reason, inherent in the nature of these compounds, why such a separation is impossible. By means of the acid brucine salt we have obtained without serious difficulty both the dextro and levo forms from the racemic $\alpha a^{\prime}$-dimethyladipic acid (m.p. $72^{\circ}$ ). Dimethyl-cyclopentanone prepared from the active acid proved to be inactive. From the ketone trimethyl-cyclopentanol was prepared by the Barbier-Griguard reaction. This loses water on distillation, or more completely on warming with anhydrous oxalic acid, giving laurolene, thus confirming Eykmann's formula for the latter and also the results previously obtained by Noyes and Derick from its oxidation.

Derivatives of Isocamphoric A.cid: W. A. NoYES and LuTher KNIGHT.

Aschan's method of preparing isocamphoric acid has been improved by using a much larger proportion of camphoric acid and decreasing the amount of hydrochioric acid in the sealed tubes. From isocamphoric acid the acid methyl esters and from this $\beta$-isocamphoramidic were prepared. The last gave, by Hofmann's reaction, an amino acid which is called, provisionally, dihydroaminoiso-a-campholytic acid. This gives with nitrous acid, not the dihydrohydroxyisocampholytic acid which was expected, but $l$-dihydrohydroxycampholytic acid identical with the same acid prepared by a different method some years ago. An unsaturated acid, probably the $d$-a-campholytic acid which was to be expected, and a lactone were also formed.

Decomposition of Nitrosophthalimidine in the Presence of Alcohol: W. A. NOYES and JAMES A. Coss.

Some years ago Noyes and Taveaur discovered that when the nitroso derivative of the anhydride of aminolauronic acid is decomposed in the presence of alcohol and sodium hydroxide a compound

$$
\left(\mathrm{C}_{8} \mathrm{H}_{14}<{ }_{\mathrm{N}\left(\mathrm{C}_{2} \mathrm{H}_{4} \mathrm{O}\right)}^{\mathrm{CO}}\right)_{2}
$$

is formed, if similar compound is obtained in small amount from nitrosophthalimidine, but the principal product is an oil which is free from nitrogen. This oil gives phthalic acid by oxidation and orthotoluic acid and ethyl iodide on heating with hydriodic acid, but its nature has not yet been fully established.

Conversion of Quinine into Quinotoxine: H. C. BIDDLe and T. B. KeLLy.

As a possible explanation of the occasional toxicity of the cinchona alkaloids, it is found that the formation of quinotoxine from quinine (so cinchotoxine from cinchonine) is determined largely by the action of certain organic acids as catalytic agents. In the presence of mineral acids 
at $100^{\circ}$, quinine shows no conversion to quinotoxine; while in the presence of many organic acids, partial conversion is effected in a few hours at temperatures as low as $30-35^{\circ}$, and appreciable conversion is shown on longer standing even at room temperature $\left(18^{\circ}\right)$. It consequently appears that under suitable conditions quinine may give rise to quinotoxine in the human system.

The reaction is of additional interest as presenting a case of catalysis by acids in which the change is apparently not affected by the hydrogen ion of the acid present.

Other papers presented for which no abstracts have been received:

The Unsaturated Character of the Resin of Pinus sabiniana: Chas. H. HeRTy and E. N. TILLeTt. A Study of the Resene of Pinus heterophylla: Chas. H. Herty, W. A. Houck and T. P. Nash. Action of Acetic Anhydride on p. Methoxy-phenylpropiolic Acid and on Methylene Ether of 3.4 Dihoxy-phenyl-propiolic Acid: MaUrice L. Dout.

The Constitution of the Oxonium Salts: M. GoMBERG.

Action of Amines on Phthalic Acid VII. Phthalamidic Acids containing $\mathrm{Cl}$ or $\mathrm{NO}_{2}$ in the Benzene Nucleus: J. BIshop TINGLE and S. J. BATES.

Camphoroxalic Acid XIII. Action of Amines on Camphoroxalic Acid: J. BIshop Tingue and S. J. BATES.

\section{DIVISION OF PHARMACEUTICAL CHEMISTRY}

Asafetida: W. A. Pearson.

Considerable analytical data are presented to illustrate the extent of variation due to sampling, methods of assay and loss in powdering. Improper sampling may be responsible for an error of 100 per cent., methods of assay about 2 per cent., while during drying preparatory to powdering a loss of approximately 20 per cent. is incurred.

Capsaicin, the Pungent Principle of Capsicum and the Detection of Capsicum: E. K. NELsoN. Capsaicin was isolated from capsicum by the method of Micko, and its properties studied.

From fifteen hundred grams of selected African pods, 2.13 grams of pure, crystalline capsaicin were obtained, representing 0.14 per cent. of the original material.

The extreme pungency of capsaicin was found to be the only property of the body of service in detecting small quantities of capsicum, and a method is proposed by the author for the detection of capsicum when used to fortify ginger preparations.

Note on the Volatility of Cocain: H. C. FuLcer.

When drying cocain residues during the process of analyzing galenical preparations, it was noted that at $100^{\circ} \mathrm{C}$. the cocain alkaloid was volatile, collecting as a sublimate on the sides of the dish and on the watch glass used as a covering. Experiments showed that there was no loss at 60,80 and 90 degrees, but at 98 degrees the cocain began to sublime and figures are given showing the gradual loss at $100^{\circ} \mathrm{C}$.

Separation and Determination of Cocain and Strychnin, and Atropin and Strychnin when they occur Together: H. C. FULLER.

The alkaloids are extracted from the drug product and weighed together, using proper precautions to obtain them in a pure condition. They are then dissolved in alcoholic potash, transferred to a pressure flask and heated over the steam bath for one hour, which completely hydrolyzes the cocain and atropin, but does not affect the strychnin. The latter is then separated and weighed.

The Correlation of the Microscopical and Chemical Analyses of Vegetable Drugs, Foods and Spices: ALBERT SCHNEIDER.

Calls attention to the value of the compound microscope as a ready means for determining the , quality and purity of foods and drugs. The relative value and significance of the chemical and microscopical analyses, is outlined. The microscopical method is of first impartance in the examination of vegetable substances of all kinds and the solid preparations made therefrom while the chemical method is of first importance in the analysis of liquids, solutions and chemicals generally. The microscopical method is quick in results, the chemical method often slow and tedious. Most analyses are incomplete without both methods. The work for the chemical analysts and the micro-analysts is outlined. The bacteriological testing of substances that require it is assigned to the micro-analyst rather than to the chemist.

Titles of other papers follow for which no abstracts have been received:

Determination of Iodine and Chlorine in Thymol Iodide by Electrolytic Means: B. L. MuRRAY. Electrolytic Determination of Mercury in the Mercury Salts of the Pharmacopoia: B. L. MuraAx. 
Ash Determinations and Ash Contents of Vegetable Drugs: Edwakd Kremers and W. H. KENDALL.

The Physiological Assay of the Heart Tonics of the Digitalis Series: E. M. Houghton.

\section{Charles L. Parsons,} Secretary

\section{SOCIETIES AND ACADEMIES}

THE AMERICAN MATHEMATICAL SOCTETY

The seventeenth summer meeting. of the society was held at Columbia University on Tuesday and Wednesday, September 6-7, 1910, extending through two sessions on each day. Thirty-six members were in attendance. Vice-president Hutchinson occupied the chair. The council announced the election of the following persons to membership in the society: Mr. F. S. Bartlett, General Electric Company, Schenectady, N. Y.; Mr. R. D. Beetle, Dartmouth C'ollege; Professor N. C. Grimes, University of Arizona; Professor F. T. H'Doubler, Miami University; Mr. Robert Henderson, Equitable Life Assurance Society, New York, N. Y.; Mr. G. F. McEwen, Stanford University; Professor Josephine A. Robinson, Berea College. Ten applications for membership in the society were received.

On Tuesday evening twenty-five of the members gathered at the usual informal dinner, always a pleasant feature of the meetings.

The following papers were read at the summer meeting :

L. E. Dickson: "On the factorization of integral functions with $p$-adic coefficients."

L. E. Dickson: "Determination of the binary modular groups and their invariants."

O. E. Glenn: "On the structure of $p$-ary forms."

R. D. Carmichael: "Linear difference equations and their analytic solutions."

H. T. Burgess: "The simultaneous reduction of a quadratic and a bilinear form by the same transformation on both $x$ 's and $y$ 's."

A. B. Coble: "On the reduction of the sextic equation to the Valentiner form problem."

Virgil Snyder: "The involutorial transformation of the plane, of order 17."

L. E. Dickson: "An invariantive investigation of irreducible binary forms."

Arthur Ranum: "On the classification of systems of linear equations."

Arthur Ranum: "The osculating sphere of a developable surface."
Peter Field: "The theory of degenerate rational plane curves."

J. E. Rowe: "Important covariant curves and a complete system of invariants of the rational cuartic curve."

G. D. Birkhoff: "General theory of linear difference equations."

I. E. Dickson: "A fundamental system of invariants of the general modular linear group on $m$ variables."

S. E. Slocum: "A general formula for the shearing deflection of beams of arbitrary cross section, either variable or constant."

G. A. Miller: "Note on the solution of a system of linear equations."

G. A. Miller: "Some relations between substitution group properties and abstract groups."

Jacob Westlund: "On the relative discriminant of a certain Kummer field."

J. W. Bradshaw: "On a method of deriving infinite products from certain infinite series."

Anna J. Pell: "Infinite systems of linear equations with unsymmetric systems of coefficients."

Edward Kasner: "Conformal invariants of curvilinear angles."

Florian Cajori: "Fourier's improvement of the Newton-Raphson method of approximation anticipated by Mourraille."

Louis Ingold: "Note on identities connecting certain integrals."

E. O. Lovett: "Generalizations of certain theorems concerning cases of collisions in the general problem of several bodies."

John Eiesland: "On minimal lines and surfaces in four-dimensional space."

John Eiesland: “Lie's line-sphere geometry from the standpoint of four-dimensional space."

E. D. Roe, Jr.: "A generalized definition of limit."

E. D. Roe, Jr.: "A new invariant function."

H. H. Mitchell: "The subgroups of the hyperorthogonal group $\mathrm{HO}\left(3, p^{2 k}\right)$."

H. Beck: "Ein Seitenstück zur Moebius'schen Geometrie der Kreisverwandtschaften."

Abstracts of the papers will appear in the November number of the Rulletin.

The San Francisco section of the society met at the University of California on Saturday, September 24. The next regular meeting of the society occurs on October 29 . The winter meeting of the Chicago section will be held at Minneapolis with the American Association.

F. N. CoLe, Secretary 